\title{
Monetary Policy Transparency: Evidence from Central Bank of Nigeria (CBN)
}

\author{
Aminu Yusuf Usman1, Umar Salisu² \\ ${ }^{1}$ Department of Economics, Kaduna State University (KASU), Kaduna, Nigeria \\ ${ }^{2}$ Department of Economics, Ahmadu Bello University, Zaria, Nigeria \\ Email: Aminuspeaker@yahoo.co.uk,Umars7781@gmail.com
}

How to cite this paper: Usman, A.Y. and Salisu, U. (2016) Monetary Policy Transparency: Evidence from Central Bank of Nigeria (CBN). Modern Economy, 7, 1070-1085. http://dx.doi.org/10.4236/me.2016.710109

Received: February 22, 2016

Accepted: September 6, 2016

Published: September 9, 2016

Copyright $\odot 2016$ by authors and Scientific Research Publishing Inc. This work is licensed under the Creative Commons Attribution International License (CC BY 4.0).

http://creativecommons.org/licenses/by/4.0/

\section{Abstract}

The idea of transparency in monetary policy has gained significant attention in the last two decades both in the academia and Central Banking Circle. As such, a number of Central Banks in the World, CBN inclusive subscribed to the trend toward a more transparent monetary policy framework. The degree of transparency is claimed to vary across Central Banks and monetary policy framework. Therefore, its effects may likely vary. This study measures monetary policy transparency using the case of Nigeria's apex Bank (CBN) by employing the Eijffinger and Geraat (2006) Index. We based our analysis on information provided by CBN from 2007-2015. The result indicates that $\mathrm{CBN}$ had a score of 11 out of 15 points. Considering the aggregate score, $\mathrm{CBN}$ can be regarded as being transparent in its monetary policy. However, looking at specific transparency dimensions, it is clear that CBN exhibits weak performance in the economic and operational dimensions which constitute important aspects of transparency. The release of accurate data on key economic variables and disclosure of policy models used for policy analysis would enhance the process of coordinating private agents' expectation toward fundamentals as well as strengthen their confidence on the monetary authority, thereby boost credibility. We recommend on this basis for CBN to partner with National Bureau of Statistics to gain access to data on unemployment and capacity utilization and on more frequent manner. This paper generally recommend that $\mathrm{CBN}$ should explicitly provide wide-ranging and accurate information on monetary policy, data on key variables relevant for policy decisions and macroeconomic model used for policy analysis in a timely and more frequent manner.

\section{Keywords}

Monetary Policy Transparency, CBN, MPC, Eijffinger-Geraat Index 


\section{Introduction}

Central Banks which have long been associated with secrecy have in recent times subscribed to the trend toward greater transparency of monetary policy. That is, the last twenty years or so witnessed greater transparency in monetary policy making and a number of Central Banks, including Central Bank of Nigeria (CBN), have adopted a more transparent monetary policy framework known as Inflation Targeting. Some Banks (e.g. US Federal Reserve) do not only subscribe to inflation targeting, but has also become much more transparent about their policymaking and operations over the past two decades [1]. In general, certain factors are responsible for the increased trend towards greater Central Bank transparency. Some of these factors are presented in [2] and [3]. It has been argued by Economists that high levels of transparency reduce uncertainty, enhance the private-sector inference about Central Bank goals, and improve the efficacy of monetary policy. Transparency can improve overall monetary policy outcomes and hence welfare. Therefore it is beneficial for the effectiveness of monetary policy [4].

Despite the fact that Central Bank transparency is considered relevant in modern monetary policy making, efforts to analyze this issue in Nigeria are yet to be significant. This paper assessed the extent of Central Bank transparency in Nigeria focusing mainly on monetary policy information provided from 2007 to 2015. The remaining components of this paper include: Section 2 which discusses the concept of monetary policy transparency, whereas Section 3 sets out the methodology for the measurement of transparency. Section 4 presents the results pertaining to the level of transparency of the Central Bank of Nigeria (CBN) on different monetary policy issues. Section 5 presents the trend of monetary policy transparency in Nigeria over the years. Section 6 concludes the discussion.

\section{Literature Review}

\subsection{Conceptual Issues}

\subsubsection{Concept of Transparency}

The concept of transparency is multi-dimensional in nature and as such defies definition across various works. For instance, transparency is defined as openness about Central Bank intentions for future interest rate decisions [5]. In another vain, Blinder et. al. [2], cited in [6] defined transparency as the ease with which the public can deduce Central Bank goals and intentions from observable data, i.e., Central Bank being fully transparent without making worded statement. In [7], transparency is defined as the absence of asymmetric information between monetary policy makers and other economic agents. However, this work regards transparency as defined in [8] as the provision of all relevant information by the Central Bank to the general public and markets on its policy strategy, assessments of economic outlook and policy decisions in an open, clear and timely manner.

\subsubsection{Dimensions of Transparency}

Five dimensions of Central Bank transparency relevant for monetary policy making are 
distinguished in [9]:

1) Political transparency: This simply means openness about formal objectives, qualitative targets and institutional arrangement.

2) Economic transparency: This is openness about the economic information the Bank uses for monetary policy (for instance data, models and internal forecasts used for policy).

3) Procedural transparency: This involves how monetary policy decisions are made (for instance strategy, minutes and voting records and capturing how policy decisions are taken).

4) Policy transparency: This refers to the prompt announcement and explanation of policy actions and inclination (For instance, in Nigeria, the Central Bank governor usually brief the general public about their decisions immediately after the MPC meeting via press conference).

5) Operational transparency: This has to do with error control, transmission disturbances and formal evaluation of policy outcome.

\subsection{Theoretical Literature}

A considerable effort was made by policy makers and academics to analyze central bank transparency in different parts of the world, mostly theoretical and conducted in advanced societies, and almost all of its written in the last decade. Theoretical evidences seem not to offer clear conclusion as regard to the optimal level and as well the benefit of Central Bank transparency. The degree of transparency differs markedly across central banks with respect to the transparency dimension and the monetary policy framework used by the Central Banks.

A number of studies argued that greater transparency is beneficial for monetary, hence it enhances welfare. Another strand of the literature argued that transparency has limits or can go too far, therefore there are situation when it can be welfare reducing and so undesirable. From the positive side of Central Bank transparency, it is argued that greater transparency improves the welfare of both the Central Bank and the public as it reduces the inflation bias [10]. It is also argued that transparency and a clear communication have the ability of reducing uncertainty in expectation. Less uncertainty reduces volatility in financial markets and hence reduces financing cost and enhances efficient allocation of resources [11]. In essence, a wide range of studies support the view that Central Bank transparency is beneficial for the effectiveness of monetary policy (for more evidence on this line of argument, see [5] [7] [12]-[18]). Some Central Banks are regarded more transparent than others (see [19]-[22]).

From the negative side, some studies argued that certainly a limit exists for Central Bank transparency (for example [2] [16] [23]). Therefore, there are situation where a certain degree of transparency might be undesirable and detrimental. Thus, retards welfare. It is argued that despite its desirability as claimed by most academics and policy makers, transparency can be harmful as it may distort policy when the central bank enjoys low-inflation credibility [24]. Also, it is shown in [13] that the social value of 
transparency regarding real shocks is negative because disclosing the private information of Central Bank may eliminates the possibility of protecting the public against those shocks. Amato et al. [24] argued that transparency may a times be welfare reducing, especially when agents give much credence to Central Bank communication which is a product of transparency and suppress their own information. Another claim in [14] was that transparency can go beyond the necessary level i.e. it can go too far. It is further indicated that a very high level of transparency might not be useful. Therefore becomes detrimental particularly when the public fail to realize its conditional nature [3] [25]. In sum, theory shows that Central Bank transparency has both positive and negative effects. However, it beneficial effects seem to outweigh its negative effects therefore can be relevant for monetary policy.

\subsection{Empirical Literature}

Empirical studies on Central Bank transparency are highly limited, especially in developing Countries like Nigeria. Hence, it is still at infant stage. Earlier studies on this issue focus mainly on describing disclosure practices of Central Banks and/or make an effort at identifying the effect of changes in disclosure practices on certain financial and economic time series variables [21]. Some recent studies attempt to compare the extent of transparency of some Central Banks of the world using a single metric index. Example includes [17] [19] [21] [22] [26].

In [19] the extent of transparency of nine major Central Banks in the world was measured using an index. The index constructed captured the five dimensions of transparency earlier provided in this work. The result reveals a different degree of transparency across the nine Central Banks and found at the top (three most transparent Central Banks in the world in 2005) as [Reserve Bank of New Zealand (RBNZ), Sveriges Riksbank (Central Bank of Sweden) and Bank of England (BoE), respectively]. At the bottom of the ranking was: Reserve Bank of Australia, Bank of Japan (BoJ) and the Swiss National Bank (Central Bank of Switzerland). Malik and Din in [17] employed the Eijffinger and Geraat index in [19] to measure the degree of transparency of the State Bank of Pakistan (SBP). Their findings ranked SBP below all the nine banks considered in [19] with a score of 4.5 out of 15. Also, in [21] this index was used but applied across 100 central banks and their result consistent with [19] places at the top: the RBNZ, Riksbank and BoE. However, some level of disparities in the scores assigned was observed. RBNZ, Riksbank and BoE scored 14, 14 and 13 respectively in the case of the [19] whereas the scores obtained by same banks in the case of [21] were respectively 13, 13 and 12. Also Czech Republic that was ranked fourth in the case of [19] was displaced by Canada in the Dincer and Eichengreen analysis. Eijffinger and Geraat do not include Canada in their study as done by Dincer and Eichengreen. Also, Dincer and Eichengreen because of their wide coverage provide new set of less transparent central banks in the world they are: Yemen which had a Score of 1 , Aruba with a Score of 0.5 and Saudi Arabia was scored 0 . 
In 2009, Dincer and Eichengreen provide an updated estimate of their 2007 scores. Their findings reveal a remarkable improvement toward greater central bank transparency. Hence, some Central Banks recorded an improvement from their 2007 score. For instance, in [22] RBNZ had a score of 14 from 13 and Saudi Arabia had 1 from 0 and so on. The limited empirical studies we come across in Nigeria has to do with [26]-[28]. In [26] and [27] the transparency of monetary policy in Nigeria was investigated using the Eijiffinger and Geraat Index whereas [28] investigated the impact of Central Bank Independence and Transparency on some macroeconomic variables in Nigeria. This study builds on [26] and [27] to provide an updated estimate of monetary policy in Nigeria. Their findings suggest a strong performance in some aspects and weak in others. The aggregated score awarded in this study is 11 out of 15 points.

\section{Methodology}

Given the multi-dimensional and qualitative nature of monetary policy transparency, measuring it objectively poses a formidable challenge to researchers in the area. Measuring the overall degree of monetary policy transparency using a widely acceptable technique in a clear and non subjective manner became close to impossible. However, it is necessary to measure the overall transparency level for the purpose of making interCountry comparison (research purpose) and for carrying out historical developments analysis (analytical purpose) [5]. In [19] an index was constructed and it combines the five dimensions of transparency as earlier stated into a single measure. Using the index, they measured and compared transparency of nine major Central Banks around the World. Following [19], [21] used it for 100 Central Banks in the World. Since then, this index has been widely employed in measuring Central Bank transparency. For instance, it was adopted in [17] to measure the degree of transparency of the State Bank of Pakistan (SBP) and in [26] [27] for Nigeria. This study also adopted this index to measure the degree of monetary policy transparency of the Central Bank of Nigeria (CBN) as at 2015. The formulation of the index is provided in Table 1.

It should be noted that Table 1 is sourced from [19].

The index provided in Table 1 was extracted from [19] and it captures the five dimensions of transparency considered in this study. In their approach, a questionnaire was developed on monetary policy issues and answered by the researcher based on information extracted from various Central Bank documents such as reports on the state of the economy, monetary policy statements, and Central Bank official's speeches. We therefore adopted this approach in our study. The questionnaire was organized to contain fifteen questions, with three questions each on the five dimensions of transparency, viz: political, economic, procedural, policy and operational transparency. An explanation on the meaning of the five indicators has been provided in section 2.1 above under dimensions of transparency. A score of 0 or 1 was awarded to six questions containing 2 options. A score of $0,1 / 2$, or 1 was awarded to nine questions having 3 options, depending on whether they satisfy certain criteria. The minimum score obtainable from the index stood at 0 and the maximum score at 15 . 
Table 1. Transparency index.

\section{S/N TRANSPARENCY DIMENSIONS}

(1)

\section{POLITICAL TRANSPARENCY}

\section{ECONOMIC TRANSPARENCY}

(a) Is there a formal statement of the objective(s) of monetary policy, with an explicit prioritization in case of multiple objectives?

(b) Is there a quantification of the primary objective(s)?

(c) Are there explicit institutional arrangements or contracts between the monetary authorities and the government?

(a) Is the basic economic data relevant for the conduct of monetary policy publicly available?

This focus on the release of data for the following five variables: money supply, inflation, GDP, unemployment rate and capacity utilization.

(b) Does the Central Bank disclose the formal macroeconomic model(s) it uses for policy analysis?

(c) Does the Central Bank regularly publish its own macroeconomic forecasts?

(a) Does the Central Bank provide an explicit policy rule or strategy that describes its monetary policy framework?

(b) Does the Central Bank give a comprehensive account of policy deliberations (or explanations

PROCEDURAL

(3) TRANSPARENCY in case of a single Central Banker) within a reasonable amount of time?

(c) Does the Central Bank disclose how each decision on the level of its main operating instrument or target was reached?

\section{RESPONSES}

No formal objective $(\mathrm{s})=0$.

Multiple objectives without prioritization $=1 / 2$.

One primary objective, or multiple objectives with explicit priority $=1$.

$$
\text { No }=0 .
$$$$
\text { Yes }=1 \text {. }
$$

No Central Bank, contracts or other institutional arrangements $=0$.

Central Bank without explicit instrument independence or contract $=1 / 2$.

Central Bank with explicit instrument independence or Central Bank contract (although possibly subject to an explicit override procedure) $=1$.

Quarterly time series for at most two out of the five variables $=0$. Quarterly time series for three or four out of the five variables $=1 / 2$. Quarterly time series for all five variables $=1$.

$$
\begin{aligned}
& \mathrm{No}=0 . \\
& \mathrm{Yes}=1 .
\end{aligned}
$$

No numerical Central Bank forecasts for inflation and output $=0$.

Numerical Central Bank forecasts for inflation and/or output published at less than quarterly frequency $=1 / 2$.

Quarterly numerical Central Bank forecasts for inflation and output for the medium term (one to two years ahead), specifying the assumptions about the policy instrument

(conditional or unconditional forecasts) $=1$.

$$
\begin{aligned}
& \mathrm{No}=0 . \\
& \mathrm{Yes}=1 .
\end{aligned}
$$

No, or only after a substantial lag $($ more than 8 weeks $)=0$. Yes, comprehensive minutes (although not necessarily verbatim or attributed) or explanations (in case of a single Central Banker), including a discussion of backward- and forward-looking arguments $=1$.

No voting records, or only after substantial lag (more than eight weeks) $=0$.

Non-attributed voting records $=1 / 2$. Individual voting records, or decision by single Central Banker $=1$. 
(4)

(5) (a) Are decisions about adjustments to the main operating instrument or target promptly announced?

(b) Does the Central Bank provide an explanation when it announces policy decisions? TRANSPARENCY

OPERATIONAL TRANSPARENCY

(c) Does the Central Bank disclose an explicit policy inclination after every policy meeting or an explicit indication of likely future policy actions (at least quarterly)?

(a) Does the Central Bank regularly evaluate to what extent its main policy operating targets (if any) has been achieved?

(b) Does the Central Bank regularly provide information on (unanticipated) macroeconomic
No, or after a significant lag $=0$.

Yes, at the latest on the day of implementation $=1$.

$$
\text { No }=0 .
$$

Yes, when policy decisions change, or only superficially $=1 / 2$.

Yes, always and including

forward-looking assessments $=1$.

$$
\begin{aligned}
& \text { No }=0 . \\
& \text { Yes }=1 .
\end{aligned}
$$

No, or not very often (at less than annual frequency) $=0$.

Yes, but without providing explanations

for significant deviations $=1 / 2$.

Yes, accounting for significant deviations from target (if any); or, (nearly) perfect control over main operating instrument $/$ target $=1$.

No, or not very often $=0$. disturbances that affect the policy transmission process?

(c) Does the Central Bank regularly provide an evaluation of the policy outcome in light of its macroeconomic objectives?
Yes, but only through short-term forecasts or analysis of current macroeconomic developments (at least quarterly) $=1 / 2$. Yes, including a discussion of past forecast errors (at least annually) $=1$.

No, or not very often

(at less than annual frequency) $=0$.

Yes, but superficially $=1 / 2$.

Yes, with an explicit account of the contribution of monetary policy in meeting the objectives $=1$.

\section{Nature and Sources of Information}

We focused mainly on monetary policy information provided by the CBN via its communication channels from 2007 to 2015. These include: CBN statistical bulletin, MPC communiqués, monthly and quarterly economic reports, financial stability reports, and so on. All of these and even more are cheaply obtain in the CBN official website: www.cenbank.org. The statistical bulletin provides information on economic variables as money supply, Gross Domestic Product (GDP), inflation and so on. As for the communiqué, a detailed explanation of the monetary policy decisions of the Nigerian monetary policy committee (MPC) is provided. Policy inclinations (tightening or easing) are clearly stated. Voting records and personal statements of the committee's members is provided as an attachment at the end of the communiqué.

\section{Transparency Level of the Central Bank of Nigeria (CBN)}

Table 2 provides a summary of the score obtained by CBN out of the total score of 15 . 
Table 2. Transparency level of CBN.

\begin{tabular}{cccc}
\hline No. & Dimension of Transparency & Highest Score & CBN Score \\
\hline $\mathbf{1}$ & Political & $\mathbf{3}$ & $\mathbf{3}$ \\
$\mathrm{a}$ & Formal Objectives & $0,0.5 \& 1$ & 1 \\
$\mathrm{~b}$ & Quantitative Targets & 0,81 & 1 \\
c & Institutional Arrangement & $0,0.5 \& 1$ & 1 \\
$\mathbf{2}$ & Economic & $\mathbf{3}$ & 1 \\
a & Economic Data & $0,0.5 \& 1$ & 0.5 \\
b & Policy Models & 0,81 & 0 \\
c & Central Bank Forecasts & $0,0.5 \& 1$ & 0.5 \\
$\mathbf{3}$ & Procedural & $\mathbf{3}$ & $\mathbf{3}$ \\
a & Explicit Strategy & 0,81 & 1 \\
b & Minutes & $0, \& 1$ & 1 \\
c & Voting Records & $0,0.5 \& 1$ & 1 \\
$\mathbf{4}$ & Policy & $\mathbf{3}$ & 2.5 \\
a & Prompt Announcement & $0, \& 1$ & 1 \\
b & Policy Explanation & $0,0.5 \& 1$ & 0.5 \\
c & Policy Inclination & $0, \& 1$ & 1 \\
$\mathbf{5}$ & Operational & $\mathbf{3}$ & $\mathbf{1 . 5}$ \\
A & Control Errors & $0,0.5 \& 1$ & 0 \\
B & Transmission Disturbances & $0,0.5 \& 1$ & 0.5 \\
C & Evaluation of Policy Outcome & $0,0.5 \& 1$ & 0.5 \\
& Total & $\mathbf{1 5}$ & 11 \\
\hline
\end{tabular}

Source: Authors' computation using the constructed index.

It also shows the score specific to each dimension of transparency while a detailed explanation on how the scores were awarded was presented in sub-section 4.1 to 4.5.

\subsection{Political Transparency}

\section{1) Formal Objectives}

The objectives of monetary policy in Nigeria are multiple. The CBN in the pursuance of its function and compliance with its core mandate undertakes monetary policy in order to: maintain Nigeria's external reserve to safeguard the international value of the domestic currency (naira) and to promote and maintain monetary stability and as well as sound and efficient financial system in Nigeria. In essence, the objective of monetary policy in Nigeria has to do with maintaining price and exchange rate stability among other objectives. This signifies multiple objectives. However, the primary objective as enshrined in the recent CBN Act (2007) is ensuring price stability which is consistent with attaining other goals of macroeconomic policy [29] [30]. This signifies explicit prioritization of the objectives and therefore a score of one was awarded.

2) Quantification of Primary Objectives 
The CBN in their respective Communiqués clearly indicates that the objective of price stability is geared toward targeting single digit inflation. This was reaffirmed in the MPC last meeting of the year 2015 where it claimed that "although headline inflation had remained at the borderline of single digit, the observed moderation, especially in the month-on-month inflation, provided some room for monetary easing to support output in the short to medium term, while keeping in focus the primacy of price stability". It is clear from this statement that the primary objective of CBN is that of achieving price stability [31]. We thus assigned a score of one.

3) Institutional Arrangement

This aspect has to do with the existence or otherwise of contracts between CBN and the government or CBN having explicit instrument independence or not. The CBN was granted operational autonomy in 1998 and full independence in 2007. In line with this, the MPC was reconstituted in 2007 and since then the Committee has been responsible for monetary policy making in Nigeria [32]. This trend continues up to 2015 and is expected to remain so in future as the outlook for the first quarter of 2016 was indicated in the last 2015 MPC meeting [31]. There seems to be explicit instrument independent and for this a score of one was awarded.

\subsection{Economic Transparency}

1) Release of Economic Data

The release of economic data involves the release of data for money supply (MS), inflation (INF), GDP, unemployment rate (UNe) and capacity utilization (CU). When all these data are provided on quarterly basis, a score of one is awarded to the Central Bank and a half score is awarded when it is for three or four out of the five variables. In the case of only two variables, zero is awarded. The CBN in its statistical bulletins publish data on all these variables except unemployment (UNe). Data on MS, INF and GDP are available on quarterly basis, while that of $\mathrm{CU}$ is on annual basis. Note that data on UNe in Nigeria is provided by the National Bureau of Statistics. As at last Quarter of 2015, CBN only publish quarterly data on three out of the five variables. Therefore, a half score was awarded.

2) Macro Economic Model

From the various CBN's documents we consulted, there is no indication of the macroeconomic model its uses for policy analysis. It appears clearly at the time of conducting this study that $\mathrm{CBN}$ is still secretive about the macroeconomic model it uses for analyzing policies in the Nigerian economy and on this note, we awarded zero on model disclosure.

3) Macro Economic Forecast

The provision of internal forecast is generally expected to reduce volatility in the markets. The MPC in its meetings usually evaluates or re-assessed the short-to-medium term risks to inflation, domestic output, external balance and financial stability. However, provision of internal forecasts for GDP and INF is mainly on short-term basis (within a year). Therefore, a half score was awarded. 


\subsection{Procedural Transparency}

1) Explicit Policy Rule

Since its inception in 1959, CBN has adopted two monetary policy frameworks namely: exchange rate targeting regime (used from 1959 to 1974) and monetary targeting regime (which has being in use since 1974 up to 2015). Certain strategies are being used by CBN in the conduct of its monetary policy and clearly stated. These strategies influence the operating, intermediate and ultimate targets via various channels and common among the strategies comprise; monetary targeting, interest rate targeting, exchange rate targeting, nominal gross domestic product or output targeting and inflation targeting. For instance, CBN provides an explanation of its policy strategy in the documents tagged understanding monetary policy, series 1, 2011 [33]. In recent times, there is a proposal for transition to full-fledged inflation targeting as the monetary policy framework [29] [30]. In essence, CBN describes its monetary policy framework explicitly and therefore, we awarded a score of one.

2) Minutes

Until in recent times, the minutes were not published by the CBN. That is the bank has recently started the publication of the minutes of its MPC meeting on its official site. The minute contain a detailed explanation of the committees' backward and forward deliberations as found in the communiqués. The decision of the committee is usually stated. It can be obtained via

http://www.cenbank.org/documents/mpc minutes.asp. On this note, we awarded a score of one on publication of minutes.

3) Voting Records

The CBN publishes its voting records but is contained in the minutes and the communiqués. For example, as part of the decisions taken in the last MPC meeting of year 2015 held on the $23 \mathrm{rd}-24^{\text {th }}$ November, it was clearly stated that 8 members out of 10 voted for reduction in Monetary Policy Rate (MPR) from $13.0 \%$ to $11.0 \%$, while 2 members voted for retention at $13.0 \%$. In addition, 7 members voted to reduce the Cash Reserve Requirement (CRR) from 25.0 per cent to 20.0 per cent while 3 members voted to hold and 8 members voted for an asymmetric corridor of $+2 /-7$ per cent while 2 voted to retain the symmetric corridor of \pm 2 per cent around the Monetary Policy Rate (MPR) [31]. Although, the publication of the voting records commenced in 2011, the publication of the minutes as well as the voting records began with the MPC meeting of January 24-25, 2011 but it is clear that voting records are published up to the end of year 2015 and is expected to continue in future [34]. In the light of this, a score of one was awarded.

\subsection{Policy Transparency}

\section{1) Prompt Announcement of Policy Decisions}

The CBN governor usually holds a press briefing immediately after each policy meeting where decisions reached and the rationale behind such decisions are provided in both the communiqués and minutes and are published on the day of meeting/imple- 
mentation of policy actions, in fact, immediately after the meeting. Changes in instruments are announced on the day of implementation. Overall policy actions are communicated immediately after the MPC meeting. Apart from the press briefing, communiqué is usually published on the CBN's official site at least 45 minutes after every meeting. We therefore awarded a score of one.

2) Explanations of Policy Decisions

CBN clearly explains its policy decisions after every MPC meetings. The press statement issued by the $\mathrm{CBN}$ governor after policy meeting provides explanation/reasons for the policy action taken. The communiqués of the meetings usually give an explicit explanation of policy actions. The policy options and the selected option are usually indicated especially in recent meetings. Changes in MPR and other rates are stated. For instance, in its meeting of 20-21 ${ }^{\text {st }}$ May, 2013, MPC is faced with the options of: a) reduction in rates in view of declining core inflation, stable exchange rates and relative reserve accretion, and b) retaining current monetary policy stance to sustain the macroeconomic gains of tight monetary policy and to continue to rein-in inflationary expect. Thus, by a majority vote of 7 members to 3, the MPC voted to retain the MPR at 12 per cent with a corridor of \pm 200 basis points; retain the CRR at 12 per cent and Liquidity Ratio at 30 per cent; with the Net Open Position at 1.0 per cent. The personal statements of all the MPC members are also in recent periods included as an attachment at the end of the communiqué. The personal statements points out the view of each member and his/her justification for taking or supporting a particular view in the meeting or voting process [34]. However, this point requires inclusion of forward looking assessments and $\mathrm{CBN}$ does not provide explicit forward looking assessments. On this note, a half score was awarded.

3) Future Direction of Policy Decisions

The CBN provides the future inclination of policy decisions in the minutes and the communiqué as well. For instance, one sees in these documents that the committee voted for either tightening or easing depending on the underlying fundamentals [35]. We therefore assigned a score of one.

\subsection{Operational Transparency}

\section{1) Control Errors}

This involves regular announcement of targets and discussions of past deviations from the target and reasons for the deviations. The CBN do publish target estimates of narrow money (M1) and broad money (M2) and some other variables on regular basis but there seems to be no clear discussions/reasons for deviations from target. From the sources we consulted, we could not trace the provision of the extent to which the main operating target of CBN has been achieved. On this ground, we assigned a score of half a mark for stating target without explanations for significant deviations.

2) Macroeconomic Disturbances

The CBN provides an analysis of past and current macroeconomic developments in the economy on both monthly and quarterly basis. Most information provided in this 
respect, is in form of explanations. An explicit discussion of past forecast errors is not usually indicated and we therefore, gave a half mark.

3) Evaluation of Policy Outcome

The CBN does not clearly indicate the actual contribution of monetary policy in realizing its macroeconomic objectives. However, it provides some superficial explanations of policy outcome. MPC discussions clearly point out whether the expected growth in indicators has been achieved in response to policy actions taken in the past. One can easily see from the discussions in the communiqué whether tightening implemented in the past has lowered inflation or remained at same digit level as before the implementation of the action. For instance, in its meeting of $18-19^{\text {th }}$, March 2013, the MPC acknowledged the achievement of single digit inflation which signifies the benefit of tightening implemented in the past as well as the overall policy coordination that helped to sustain the improvement recorded in macroeconomic indicators [36]. Also, MPC noted despite tightening stance taken in the past that the year-on-year headline inflation rose to 9.3 per cent in August, from 9.2 per cent in June and July, 2015. The increase in headline inflation in August reflected marginal increases in both the core and food components of inflation. Core inflation rose to 9.0 per cent in August from 8.8 per cent in July, while food inflation increased to 10.1 per cent from 10.05 per cent over the same period [37]. However, CBN failed to provides an explicit account of the contribution of monetary policy in meeting the macroeconomic objectives. On this note, we awarded a half mark on policy outcome evaluation.

Finally, we awarded CBN a total score of 11 out of 15 as shown in Table 2. An area where $\mathrm{CBN}$ is found to be least transparent is economic and operational dimensions; each obtained a score of 1 and 1.5 respectively. In the case of the economic aspect, the score of 1.5 was obtained by option (a) and (c) respectively i.e. the release of economic data and forecasts and zero policy models. For the operational dimension, 0.5 was awarded to all the three options of control errors, transmission disturbances and evaluation of policy outcome. The dimensions of political and procedural happen to contribute more to the total score obtained. A score of 3 was obtained in either case. This indicates a full transparency in those aspects. Therefore both dimensions contributed 6 scores out of the aggregate score of 11 obtained. The other three dimensions contributed only 4 points out of the aggregate score of 9.5 .

\section{Trends in Monetary Policy Transparency in Nigeria}

Empirical evaluation of monetary policy transparency in the case of Nigeria shows significant improvement in the last decade. An assessment of Central Banks' transparency level in Africa in

[21] shows an improvement on the part of Nigeria in the first half of last decade. Nigeria, who had a score of 3 points from 1999 to 2002 consecutively, rose to 5 points in 2003 through 2005 in succession (see Table 3).

More recent studies suggest stronger performance from 2007 to 2010. This cannot be unconnected to the developments experienced in the general conduct of monetary policy in the Country within that period. For instance, the introduction of MPR in late 
Table 3. Central bank transparency level in Africa.

\begin{tabular}{|c|c|c|c|c|c|c|c|c|c|}
\hline NO. & COUNTRY & 1998 & 1999 & 2000 & 2001 & 2002 & 2003 & 2004 & 2005 \\
\hline 1 & ETHIOPIA & 1.7 & 1.8 & 1.9 & 2.4 & 2.6 & 2.6 & 2.6 & 2.8 \\
\hline 2 & EGYPT & 1 & 1 & 1 & 1 & 1 & 1 & 1 & 1 \\
\hline 3 & GHANA & 3 & 3 & 3 & 3 & 3 & 5 & 5 & 5 \\
\hline 4 & KENYA & 2 & 2 & 2.5 & 4.5 & 4.5 & 4.5 & 4.5 & 4.5 \\
\hline 5 & LESOTHO & 1 & 1 & 1.5 & 1.5 & 1.5 & 2.5 & 2.5 & 4.5 \\
\hline 6 & LIBYA & 1 & 1 & 1 & 1 & 1 & 1 & 1 & 1 \\
\hline 7 & MALAWI & 0.5 & 0.5 & 0.5 & 2.5 & 2.5 & 2.5 & 2.5 & 2.5 \\
\hline 8 & MAURITIUS & 3.5 & 3.5 & 3.5 & 3.5 & 3.5 & 3.5 & 3.5 & 3.5 \\
\hline 9 & NAMIBIA & 4 & 4 & 4.5 & 4.5 & 4.5 & 4.5 & 4.5 & 4.5 \\
\hline 10 & NIGERIA & 3 & 3 & 3 & 3 & 3 & 5 & 5 & 5 \\
\hline 11 & RWANDA & 1.5 & 1.5 & 1.5 & 1.5 & 1.5 & 1.5 & 1.5 & 1.5 \\
\hline 12 & $\begin{array}{l}\text { SOUTH } \\
\text { AFRICA }\end{array}$ & 4 & 4 & 5 & 9 & 9 & 9 & 9 & 9 \\
\hline 13 & SUDAN & 1 & 1 & 2 & 2 & 2 & 2 & 2 & 2 \\
\hline 14 & $\begin{array}{l}\text { SIERRA } \\
\text { LEONE }\end{array}$ & 1.5 & 1.5 & 1.5 & 1.5 & 1.5 & 1.5 & 1.5 & 1.5 \\
\hline 15 & TUNISIA & 2.5 & 2.5 & 2.5 & 2.5 & 4 & 4 & 4 & 4 \\
\hline 16 & UGANDA & 2 & 2.5 & 2.5 & 2.5 & 2.5 & 2.5 & 2.5 & 2.5 \\
\hline 17 & ZAMBIA & 1.5 & 1.5 & 1.5 & 1.5 & 1.5 & 1.5 & 1.5 & 1.5 \\
\hline
\end{tabular}

Source: Adapted from [21].

2006 to replace Minimum Rediscount Rate (MRR) and reconstitution of MPC in 2007 when $\mathrm{CBN}$ was granted full independence mark a new policy framework and communication regime. These recent developments of CBN's autonomy as stated in the new CBN Act of 2007 support Central Bank independence and transparency in Nigeria. Thereby, making the CBN and its policy decisions more open [32]. Therefore CBN had a remarkable change in its communication policy especially from 2007 to 2015 . An empirical study by [26] reveals a good overall performance, in which CBN had a score of 11.5 out of 15 points.

This paper made a similar attempt to provide an updated estimate, where the CBN transparency is assessed by updating our information to the last MPC meeting of year 2015. However, our result is slightly different from that of Egbuna by 0.5 . We had an aggregated score of 11 points out of 15 . Therefore our score is less by 0.5 . The source of the disparity arises from economic transparency and under macro economic forecast. Under that, it is required that for a Central Bank to earn a full mark of one point, it must provides quarterly numerical forecast for inflation and GDP for the medium term (one to two years ahead), specifying clearly the assumptions about policy instruments. Egbuna awarded one in this aspect but we assigned a half mark. Because the provision of internal forecasts for GDP and INF in the communiqués of monetary policy is mainly on short-term basis (within a year). For instance, in the MPC meeting of May $20-21^{\text {st }}, 2013$, the Committee noted that the relatively robust output growth projection 
for 2013 was hinged on expected favorable conditions for increased agricultural production and other policy initiatives aimed at stimulating the economy. The inflation outlook remains relatively benign with projections of headline inflation remaining in the single digit range for the next six months. The information on both variables is usually in the form of verbal projections and mostly within a year; quarterly or six months ahead. Comparing the result of [26] and of this study, one can infer by claiming the inexistence of significance improvement in the disclosure of monetary policy decisions in the last four years. However, previous strategies and disclosure practices are maintained.

\section{Conclusion}

This study assessed the level of monetary policy transparency of the CBN using the Eijjfinger and Geraat index. The CBN is found to be more transparent in some areas and deficient in others. The CBN shows stronger performance in the areas of political, procedural and policy dimensions and less transparent in economic and operational dimensions. Considering the overall level of transparency obtained in this study, we regard CBN as being transparent. There is a remarkable improvement in the overall degree of CBN's transparency from 2000-2011. However, there still exists a room for improvement especially in the areas of economic and operational dimensions as suggested by Egbuna about 5 years ago. This study found no evidence of improvement in such aspects. We therefore re-emphasized earlier suggestions in these areas and further recommend the release of accurate and complete data on key economic variables and disclosure of policy models used for policy analysis. These would enhance the process of coordinating private agents' expectation toward fundamentals as well as strengthen their confidence on the monetary authority, thereby boost credibility. The frequency at which data on some variables as capacity utilization are provided needs to be enhanced to at least quarterly basis. Also, CBN needs to partner with agencies as National Bureau of Statistics in order to gain access to data on variables as unemployment at appreciable frequencies. With regards to operational transparency, efforts need to be made on the three aspects viz; control errors, transmission disturbances and evaluation of policy outcomes. Regular announcement of targets and discussions of past deviations from the target and reasons for the deviations are necessary, therefore informations on this need to be provided by CBN. An explicit discussion of past forecast errors is relevant for operational transparency. Also, an explicit account of the contribution of monetary policy in meeting the macroeconomic objective is equally relevant for this aspect. Therefore, CBN also needs to improve these three measures. In a more general note, CBN should explicitly provide accurate information on monetary policy decisions in a timely and frequent manner. This can help guide the inflation expectations of agents, and reduce information asymmetries and market failure. Further studies can empirically evaluate the impact of monetary policy transparency on asset prices.

\section{References}

[1] Meade, E.E. and Stasavage, D. (2008) The Dangers of Increased Transparency in Monetary 
Policymaking. The Economic Journal, 118, 695-717.

http://dx.doi.org/10.1111/j.1468-0297.2008.02138.x

[2] Blinder, A.S., Ehrmann, M., Frazscher, M., De-Haan, J. and Jansen, D.J. (2008) CBC and Monetary Policy: A Survey of Theory and Evidence. European Central Bank Eurosystem, Working Paper Series No. 898.

[3] Ferrero, G. and Secchi, A. (2007) The Announcement of Future Policy Intentions?

[4] De Mendonca, H.F. and Filho, J.S. (2008) Macroeconomic Effects of Central Bank Transparency: The Case of Brazil. Cato Journal.

[5] Qvistad, J.F. (2008) Transparency and Central Bank Communication. Speech by Mr Jan F. Qvistad (Deputy Governor), Norges Bank (Central Bank of Norway) at a Seminar in the Bank of Italy, Rome on $4^{\text {th }}$ November, 2008.

[6] Faust, J. and Svensson, L.E. (2001) Transparency and Credibility: Monetary Policy with Unobservable Goals. National Bureau of Economic Research (NBER) Working Paper.

[7] Geraats, P.M. (2002) Central bank Transparency. The Economic Journal, 112, F532-F565. http://dx.doi.org/10.1111/1468-0297.00082

[8] Begg, I. (2006) Economic Policy and Institutional Transparency: The European Central Bank. European Institute, London School of Economics and Political Science.

[9] Eijffinger, S.C.W. and Geraat, P.M. (2006) How Transparent are Central Banks. European Journal of Political Economy, 22, 1-21. http://dx.doi.org/10.1016/j.ejpoleco.2005.09.013

[10] Sibert, A.C. (2006) Is Central Bank Transparency Desirable? CEPR Discussion Paper.

[11] Lamla, M. and Rupprecht, S.M. (2007) The Impact of ECB Communication on Financial Market Expectations.

[12] Faust, J. and Svensson, L.E. (1998) Transparency and Credibility: Monetary Policy with Unobservable Goals. National Bureau of Economic Research (NBER) Working Paper.

[13] Gersbach, H. (2002) On the Negative Social Value of Central Banks' Transparency. University of Heidelberg (Working Paper).

[14] Mishkin, F.S. (2004) Can Central Bank Transparency Go Too Far? In: Kent, C. and Guttmann, S., Eds., The Future of Inflation Targeting, Reserve Bank of Australia, 48-65.

[15] Carpenter, S.B. (2004) Transparency and Monetary Policy: What Does the Academic Literature Tell Policymakers? Finance and Economics Discussion Series, 2004-35, Board of Governors of the Federal Reserve System.

[16] Nijathaworn, B. (2006) Are There Limits to Transparency? IMF Conference on Central Bank Communication, 23-24 January 2006, Mumbai, India.

[17] Malik, W.S. and M. Din. (2008) Monetary Policy Transparency in Pakistan: An Independent Analysis. PIDE Working Papers, 44.

[18] Ehrmann, M., Eijffinger, S. and Fratzscher, M. (2010) The Role of Central Bank Transparency for Guiding Private Sector Forecasts. ECB Working Paper Series.

[19] Eijffinger, S.C.W. and Geraat, P.M. (2006) How Transparent Are Central Banks. www.sciencedirect.com

[20] Reeves, R. and Sawicki, M. (2007) Do Financial Markets React to Bank of England Communication? European Journal of Political Economy, 23, 207-227. http://dx.doi.org/10.1016/j.ejpoleco.2006.09.018

[21] Dincer, N. and Eichengreen, B. (2007) Central Bank Transparency: Where, Why, and with What Effects? National Bureau of Economic Research (NBER), Working Paper 13003.

[22] Dincer, N. and Eichengreen, B. (2009) Central Bank Transparency: Causes, Consequences 
and Update. National Bureau of Economic Research.

[23] Kahneman, D. (2003) Maps of Bounded Rationality: Psychology for Behavioural Economics. American Review, 93, 1449-1475.

[24] Jensen, H. (2001) Optimal Degrees of Transparency in Monetary Policy-Making: The Case of Imperfect Information about the Cost-Push Shock. (Mimeographed)

[25] Amato, J.D., Morris, S. and Shin, H.S. (2003) Communication and Monetary Policy. Cowles Foundation Discussion Paper No. 1405.

[26] Egbuna, E.N. (2011) An Empirical Analysis of Transparency of Monetary Policy in Nigeria. Nigerian Journal of Economic and Social Studies (NJESS), 53, 167-191.

[27] Salisu, U. (2012) Impact of Central Bank Communications on Stock Prices in Nigeria. Unpublished Msc Thesis, Department of Economics Ahmadu Bello University, Zaria.

[28] Oloni and Adewara (2013) Transition to Full-Fledged Inflation Targeting: A Proposed Programme for Implementation by the Central Bank of Nigeria. Occasional Paper No. 44.

[29] Monetary Policy Review (2014) Central Bank of Nigeria.

[30] Ojo, M.O. (2013) Macroeconomic Effects of Central Bank Independence and Transparency: The Case of Nigeria. Journal of Economics and Sustainable Development, 4, 18-27.

[31] Central Bank of Nigeria (CBN) MPC Communiqué. No. 104.

[32] Sanusi, A.R. (2011) Signaling Vs Cost-of-Fund Effects of Monetary Policy in Nigeria: Evidence from the Post Banking Sector Consolidation Data. 2011 Annual Conference of the Faculty of Administration, Nassarawa State University, Keffi, 17-19 May 2011.

[33] CBN (2011) Understanding Monetary Policy Transparency. Series No. 1.

[34] Central Bank of Nigeria (CBN) MPC Communiqué. No. 74.

[35] Central Bank of Nigeria (CBN) MPC Communiqué. No. 96.

[36] Central Bank of Nigeria (CBN) MPC Communiqué. No. 88.

[37] Central Bank of Nigeria (CBN) MPC Communiqué. No. 103.

Submit or recommend next manuscript to SCIRP and we will provide best service for you:

Accepting pre-submission inquiries through Email, Facebook, LinkedIn, Twitter, etc.

A wide selection of journals (inclusive of 9 subjects, more than 200 journals)

Providing 24-hour high-quality service

User-friendly online submission system

Fair and swift peer-review system

Efficient typesetting and proofreading procedure

Display of the result of downloads and visits, as well as the number of cited articles

Maximum dissemination of your research work

Submit your manuscript at: http://papersubmission.scirp.org/ 